\title{
Sustainability and environmental enhancement in changing circumstances
}

\author{
LU Yong-long, SHI Ya-juan \\ Research Center for Eco-Environmental Sciences, Chinese Academy of Sciences, Beijing 100085, China Email: yllu@ rcees.ac.cn
}

Natural environment has endured fast economic growth and population explosion since the 20th century, which has brought a lot of problems. Global environmental change, soil erosion, land desertification, ozone layer depletion, bio-diversity reduction and persistent toxic and harmful pollutants are among the major environmental challenges.

With the rapid industrialization and urbanization in developing countries, there are many big problems appearing that are related to environment, such as ecological security, food security and human health. Realization of sustainable development and harmony between man and nature has become the common goal and mission that is facing the governments, enterprises, science communities and the public. Nowadays, development with a scientifically sound manner is promoted across China. Interactions between the western and eastern economies, and developed and developing regions, are encouraged to bridge the gap, and to build a harmonious society. China is faced with a new opportunity for reaching towards harmony between environment and development.

In this context, the Third International Conference on Environmental Enhancement and Sustainable Development was held in Hohhot from Aug. 4-8, 2006. The conference was sponsored by the China Association for Science and Technology, Scientific Committee on Problems of the Environment (SCOPE), and National Natural Science Foundation of China, and organized jointly by Chinese Committee for SCOPE, Inner Mongolia, Gansu, Ningxia, Qinghai, Shaanxi and Xinjiang Associations for Science and Technology. It was co-chaired by Professor Yonglong Lu, Secretary-general of Chinese Committee for SCOPE, Prof. Linhe Wang, President of Inner Mongolia Association for Science and Technology, and Dr. Veronique P. Fichelet, Executive Director of SCOPE. The co-chairs emphasized the importance of creating a platform for exchanging ideas and presenting proposals for sustainable development in a changing environment, and fostering a good mechanism to understand the significance of ecosystem health for sustainable development, to explore theory and methodology for the harmonious development between human and nature, to identify the impacts of Persistent Toxic Substances (PTS) on ecosystem and human health and policy tools, and to review the science and technology progress in resource exploitation, economic development and environmental protection.

The conference was attended by more than 200 participants from academia, business and industries, governments and non-governmental organizations. This diverse group of people got together in plenary or break-out sessions to share their knowledge, technology and experiences in addressing the following topics:

\section{Ecosystem management and ecological security}

Biodiversity and ecosystem service functioning; Restoration of degraded ecosystems and preservation of ecological reserves; Prediction, pre-warning and reporting systems of natural hazards; Ecosystem health evaluation and integrated ecosystem management

\section{Resource utilization and sustainable development}

Theory and methodology for rational allocation and sustainable use of water resources; Grassland and land resources for sustainable agricultural and husbandry development; Rational use of energy resources and energy development strategies; Assessment of tourist resources and sustainable tourism development

\section{West development and environmental rebuilding}

Metropolitan development and demonstrative radiation effects; Strategies for East-West interaction and environmental impacts; Industrialization, urbanization and environmental health effects; Optimization of industrial structure and recycling economy

\section{Persistent toxic substances (PTS) and environmental health policy}

Impacts of PTS on environment health; Fate, persistence, distribution and eco-toxicological impacts; Policy implications: control and management.

Some of the selected papers addressing the above topics are being published in this issue of the Journal of Environmental Sciences, with focus on Sustainability and Environmental Enhancement in Changing Circumstances from different perspectives. Some of the papers presented at the conference, on persistent toxic substances and environmental health policy, will be devoted to a special issue in another peer-reviewed journal. Statements made in these papers are those of the individuals and do not necessarily reflect the opinions of the sponsoring organizations, and also presented in a scientific manner.

In finalizing the editing of this special issue, we are grateful to the conference Academic Committee and Organizing Committer for their helpful insights and practical assistances. Thanks are given to the China Association for Science and Technology and National Natural Science Foundation of China for their generous financial support. Special thanks are given to Prof. Yingnan Liang and Ms. Hong Zhang for their encouragement and support. 